\title{
Nocturnal Sleep Onset Rapid Eye Movement Sleep Periods as a Predictor of the Severity of Narcolepsy in Korea
}

\author{
Jihyun Song ${ }^{1 *}$, Tae-Won Kim, MD ${ }^{1,2 *}$, Sung Min Kim, MD ${ }^{1,2}$, Yoo Hyun Um, MD, PhD ${ }^{1,2}$, Jong-Hyun Jeong, MD, PhD ${ }^{1,2}$, \\ Ho-Jun Seo, MD, PhD ${ }^{1,2}$, Ji Hye Oh, MD ${ }^{1,2}$, Seung Chul Hong, MD, PhD ${ }^{1,2}$ \\ 'Sleep Disorders Clinic, St. Vincent's Hospital, The Catholic University of Korea, Suwon, Korea \\ 'Department of Psychiatry, St. Vincent's Hospital, College of Medicine, The Catholic University of Korea, Suwon, Korea
}

Received: October 7, 2019
Revised: December 1, 2019
Accepted: December 15, 2019
Correspondence
Seung Chul Hong, MD, PhD
Department of Psychiatry,
St. Vincent's Hospital,
College of Medicine,
The Catholic University of Korea,
93 Joongbudae-ro,
Suwon 16247, Korea
Tel +82-31-249-7114
Fax +82-31-248-6758
E-mail hscjohn@hotmail.com
*These authors contributed equally to this work.

ORCID

Jihyun Song

https://orcid.org/0000-0002-0128-2869

Tae-Won Kim

https://orcid.org/0000-0003-2689-202X Sung Min Kim

https://orcid.org/0000-0002-3082-4014 Yoo Hyun Um

https://orcid.org/0000-0002-3403-4140

Jong-Hyun Jeong

https://orcid.org/0000-0003-3570-7607

Ho-Jun Seo

https://orcid.org/0000-0003-1661-1394 Ji Hye Oh

https://orcid.org/0000-0002-6865-3935

Seung Chul Hong

https://orcid.org/0000-0003-0828-2906

(C) This is an Open Access article distributed under the terms of the Creative Commons Attribution Non-Commercial License (https://creativecommons.org/licenses/by-nc/4.0) which permits unrestricted non-commercial use, distribution, and reproduction in any medium, provided the original work is properly cited.
Background and Objective To investigate the severity of narcolepsy based on the presence of nocturnal sleep onset rapid eye movement sleep period (nSOREMP).

Methods Subjects included 167 narcolepsy patients diagnosed at the St. Vincent Hospital, the Catholic University of Korea. They underwent polysomnography (PSG) and Multiple Sleep Latency Test (MSLT). The standardized face to face interview and Epworth Sleepiness Scale were used to inquire about daytime sleepiness of patients. Overall retrospective chart review was performed on their sleep health data.

Results The presence of nSOREMP was highly correlated with short mean sleep latency and high number of SOREMPs in MSLT. Subjects with nSOREMP also demonstrated higher percentage of N1 sleep, lower percentage of N2 sleep, and more frequent arousals in PSG. They also showed higher prevalence of cataplexy and human leukocyte antigen DQB1*06:02 positivity.

Conclusions Subjects with nSOREMP showed more excessive daytime sleepiness and lower quality of sleep compared to subjects without nSOREMP. Our results suggest that nSOREMP might be a severity marker of narcolepsy.

Sleep Med Res 2020;11(1):19-24

Key Words Multiple sleep latency test, Nocturnal sleep onset rapid eye movement, Sleep period, Nocturnal polysomnography, Narcolepsy, Cataplexy.

\section{INTRODUCTION}

Narcolepsy is a chronic neurological disorder characterized by excessive daytime sleepiness, rapid eye movement (REM) sleep dysregulation, and nighttime sleep disturbances. Since it occurs in $0.02-0.05 \%$ of population, accurate diagnosis and treatment are challenged [1]. Meanwhile, several studies have disclosed that nocturnal sleep onset rapid eye movement sleep period (nSOREMP) appearing in nocturnal polysomnography (PSG) is highly specific to narcolepsy $[2,3]$. The specificity of nSOREMP in narcoleptics is nearly $97 \%$ (97.8\% [3] in adult population and $97.3 \%$ [2] in pediatric population). Like above, the diagnostic value and utility of nSOREMP have been continuously identified in various age and race groups, especially in diagnosing narcolepsy with cataplexy [4,5].

Following such findings, international classification of sleep disorders third edition (ICSD-3) has updated the diagnostic criteria and stated that nSOREMP may substitute one of SOREMPs in Multiple Sleep Latency Test (MSLT) when diagnosing narcolepsy [6]. However, few studies have explored homogeneous features of nSOREMP positive group.

Thus, the objective of this study was to investigate whether the presence of nSOREMP might be associated with diagnostic and clinical characteristic of narcolepsy. We defined such characteristics including the presence of cataplexy, higher Epworth Sleepiness Scale (ESS), shorter 
mean sleep latency (SL), and higher number of SOREMPs in MSLT as symptom severity. The aim of this study was to evaluate the severity of narcolepsy based on the presence of nSOREMP.

\section{METHODS}

\section{Participants and Patient Evaluation}

A chart review was conducted for 167 narcolepsy patients who visited the sleep clinic in St. Vincent's Hospital, the Catholic University of Korea. All subjects were categorized into two groups based on the presence of nSOREMPs. These subjects were further categorized into four groups by the type of narcolepsy: Type 1 Narcolepsy (T1N) with nSOREMP $(\mathrm{n}=52), \mathrm{T} 1 \mathrm{~N}$ without nSOREMP ( $\mathrm{n}=44$ ), Type 2 Narcolepsy (T2N) with nSOREMP $(\mathrm{n}=13)$, and T2N without $\mathrm{nSOREMP}(\mathrm{n}=58)$. A diagnosis of T1N and T2N was made using ICSD-3. Confirmation on the presence of cataplexy and objective measurement of sleep was completed by a sleep medicine specialist. Subjects with any history of medical disorder associated with excessive daytime sleepiness were excluded. At their baseline, all participants were drugnaïve. They were asked to stop prescribed medication or over-thecounter drugs for 14 days before PSG and MSLT. All participants gave written informed consent for participating in this study after obtaining approval from the by Institutional Review Board of St. Vincent's Hospital, the Catholic University of Korea (VC20RISI0061).

\section{Diagnostic Test and Evaluation}

All patients underwent PSG and MSLT for objective sleep parameter. They were also asked to fill out ESS in order to measure excessive daytime sleepiness. Human leukocyte antigen (HLA) typing was also performed. The presence or absence of DQB1*06:02 was determined using DQB1 exon-2 sequencespecific primers [7]. Diagnostic findings included the following: 1) demographic characteristics such as age, body mass index (BMI), sex, and HLA DQB1*06:02 typing; 2) daytime sleepiness such as ESS, number of naps, and the presence of cataplexy; 3) MSLT such as mean SL and number of SOREMPs; 4) nocturnal PSG, such as time in bed (TIB), total sleep time (TST), sleep efficiency (SE), SL, apnea hypopnea index (AHI), periodic limb movement index (PLMI), total arousal index (TAI), number of awakenings, REM latency, percentage of stage N1 sleep (N1), stage N2 sleep (N2), REM sleep, and slow wave sleep. Diagnostic features of subjects were studied by categorizing data based on the presence of nSOREMP and the type of narcolepsy.

\section{Statistical Analysis}

Subjects were first categorized into two groups by the presence of nSOREMP. They were then subcategorized by the type of narcolepsy. Normality of each group was represented with mean and standard deviation according to skew statistics. We used one-way analysis of covariance for normative data and the Kruskal-Wallis test for data with a marginally skewed distribution. These analyses proceeded under controlling covariate, HLA DQB1*06:02 genotype. All analyses were conducted with SPSS version 18 (SPSS Inc., Chicago, IL, USA) with an a value of 0.05 for all tests.

\section{RESULTS}

\section{Comparison between nSOREMP Positive and Negative Groups}

Demographic, laboratorial characteristics, and clinical characteristics of narcolepsy patients based on the presence of nSOREMP are listed in Table 1. nSOREMP was present in 65 (38.92\%) of 167 subjects, while it was absent in 102 (61.07\%) subjects. The age of participants ranged from 13 years to 67 years, with a mean age of $29.03 \pm 13.00$ years. In the nSOREMP positive group, $58.46 \%$ of subjects were males. Average BMI was $24.37 \pm 3.35$ in the nSOREMP positive group. In the nSOREMP negative group, $64.71 \%$ were males. The average BMI was 24.18 \pm 4.17 in the nSOREMP negative group. We did not detect any significant difference in age, BMI, or sex between the two groups. However, the nSOREMP positive group showed significantly higher HLA DQB1*06:02 positivity compared to the nSOREMP negative group $(\mathrm{p}<0.05)$. In the nSOREMP positive group, $77.42 \%$ of subjects showed HLA positivity while $42.50 \%$ of subjects showed HLA positivity in the nSOREMP negative group. Of daytime sleepiness parameters, there was no significant difference in ESS or the number of naps (both $p=0.15$ ) between nSOREMP positive and negative groups. However, prevalence of cataplexy was significantly higher in the nSOREMP positive group than that in the nSOREMP negative group $(80.00 \%$ vs. $43.14 \%, \mathrm{p}<0.05)$.

Sleep parameters measured by MSLT showed significant difference between the two groups. The nSOREMP positive group demonstrated significantly shorter MSL and higher number of SOREMPs in MSLT compared to the NSOREMP negative group (both $\mathrm{p}<0.05$ ). MSL and the number of SOREMPs in MSLT of the nSOREMP positive group were $1.62 \pm 1.15 \mathrm{~min}$ and 3.53 \pm 0.69 , respectively. Those in the nSOREMP negative group were $4.26 \pm 2.66 \mathrm{~min}$ and $2.48 \pm 0.97$, respectively.

Of nocturnal PSG data, there was no significant difference in TIB, TST, or SE ( $p=0.7, p=0.15, p=0.14$, respectively). Meanwhile, percentage of $\mathrm{N} 1$ was significantly higher in the nSOREMP positive group $(p=0.001)$. Percentage of N1 was $10.53 \pm 5.90$ in the nSOREMP positive group, while it was $7.59 \pm 5.64$ in the nSOREMP negative group. However, percentage of $\mathrm{N} 2$ was significantly higher in the nSOREMP negative group $(\mathrm{p}=0.003)$. Sleep in the nSOREMP positive group contained $50.63 \pm 10.06 \%$ of $\mathrm{N} 2$, while sleep in the nSOREMP negative group contained $55.35 \pm 8.78 \%$ of $\mathrm{N} 2$. There was no significant difference in slow 
Table 1. Demographic, clinical, and laboratorial findings of narcolepsy patients based on the presence of nSOREMP

\begin{tabular}{|c|c|c|c|}
\hline Presence of SOREMP & Present $(n=65,38.92 \%)$ & Absent $(n=102,61.07 \%)$ & p-value \\
\hline \multicolumn{4}{|l|}{ Demographic data } \\
\hline Age, mean $\pm \mathrm{SD}$ (years) & $29.72 \pm 13.04$ & $27.87 \pm 13.33$ & 0.38 \\
\hline $\mathrm{BMI}$, mean $\pm \mathrm{SD}\left(\mathrm{kg} / \mathrm{m}^{2}\right)$ & $24.37 \pm 3.35$ & $24.18 \pm 4.17$ & 0.75 \\
\hline Sex (male, \%) & 58.46 & 64.71 & 0.42 \\
\hline HLA-DQB1*06:02 (+, \%) & $77.42(\mathrm{n}=53)$ & $42.50(\mathrm{n}=77)$ & $<0.05$ \\
\hline \multicolumn{4}{|l|}{ Daytime functioning } \\
\hline ESS & $14.88 \pm 3.82(n=50)$ & $15.89 \pm 3.24(\mathrm{n}=78)$ & 0.15 \\
\hline Number of naps & $5.89 \pm 3.24(\mathrm{n}=39)$ & $5.21 \pm 2.78(\mathrm{n}=53)$ & 0.15 \\
\hline Cataplexy (present, \%) & 80.00 & 43.14 & $<0.05$ \\
\hline \multicolumn{4}{|l|}{ MSLT } \\
\hline Mean sleep latency (min) & $1.62 \pm 1.15$ & $4.26 \pm 2.66$ & $<0.05$ \\
\hline SOREMPs in MSLT, mean \pm SD & $3.53 \pm 0.69$ & $2.48 \pm 0.97$ & $<0.05$ \\
\hline \multicolumn{4}{|l|}{ Nocturnal PSG } \\
\hline $\mathrm{TIB}$, mean $\pm \mathrm{SD}(\min )$ & $459.54 \pm 32.48$ & $461.45 \pm 28.06$ & 0.70 \\
\hline $\mathrm{TST}$, mean $\pm \mathrm{SD}(\mathrm{min})$ & $427.37 \pm 50.43$ & $438.39 \pm 42.09$ & 0.15 \\
\hline $\mathrm{SE}$, mean $\pm \mathrm{SD}(\%)$ & $92.55 \pm 8.29$ & $94.40 \pm 6.89$ & 0.14 \\
\hline $\mathrm{N} 1$, mean $\pm \mathrm{SD}(\%)$ & $10.53 \pm 5.90$ & $7.59 \pm 5.64$ & $<0.05$ \\
\hline $\mathrm{N} 2$, mean $\pm \mathrm{SD}(\%)$ & $50.63 \pm 10.06$ & $55.35 \pm 8.78$ & $<0.05$ \\
\hline SWS, mean \pm SD (\%) & $6.99 \pm 8.54$ & $4.76 \pm 6.66$ & 0.06 \\
\hline $\mathrm{REM}$, mean $\pm \mathrm{SD}(\%)$ & $21.59 \pm 7.24$ & $20.41 \pm 5.55$ & 0.24 \\
\hline $\mathrm{REML}$, mean $\pm \mathrm{SD}(\mathrm{min})$ & $3.38 \pm 3.55$ & $92.55 \pm 43.02$ & $<0.05$ \\
\hline $\mathrm{SL}$, mean $\pm \mathrm{SD}(\mathrm{min})$ & $3.19 \pm 3.14$ & $7.32 \pm 9.91$ & $<0.05$ \\
\hline $\mathrm{AHI}$, mean $\pm \mathrm{SD}(/ \mathrm{h})$ & $1.74 \pm 6.90$ & $1.29 \pm 4.97$ & 0.63 \\
\hline $\mathrm{PLMI}$, mean $\pm \mathrm{SD}(/ \mathrm{h})$ & $6.58 \pm 15.03$ & $3.09 \pm 9.33$ & 0.07 \\
\hline Number of awakenings & $8.33 \pm 9.04$ & $6.02 \pm 6.35$ & 0.06 \\
\hline TAI & $13.65 \pm 10.20$ & $10.54 \pm 7.08$ & $0.03^{* *}$ \\
\hline
\end{tabular}

** $\mathrm{p}<0.05$.

BMI: body mass index, ESS: epworth sleepiness scale, MSLT: multiple sleep latency test, nSOREMPS: nocturnal sleep-onset rapid eye movement periods, PSG: polysomnography, TIB: time in bed, TST: total sleep time, SE: sleep efficiency, N1: stage 1 sleep, N2: stage 2 sleep, SWS: slow wave sleep, REM: rapid eye movement, REML: rapid eye movement latency, SL: sleep latency, AHI: apnea hypopnea index, PLMI: periodic limb movement index, TAI: total arousal index, SD: standard deviation, HLA: human leukocyte antigen.

wave or REM sleep between the two groups $(\mathrm{p}=0.06, \mathrm{p}=0.24$, respectively). REM latency and SL were significantly shorter in the nSOREMP positive group (both $\mathrm{p}<0.05$ ). REM latency and SL in the nSOREMP positive group were $3.38 \pm 3.55 \mathrm{~min}$ and $3.19 \pm 3.14 \mathrm{~min}$, respectively. In the nSOREMP negative group, REM latency and SL were $92.55 \pm 43.02 \mathrm{~min}$ and $7.32 \pm 9.91 \mathrm{~min}$, respectively. Differences in AHI, PLMI, and the number of awakenings were not statistically significant between the two groups. However, TAI was higher in the nSOREMP positive group than that in the nSOREMP negative group $(13.65 \pm 10.20$ vs. $10.54 \pm$ $7.08, \mathrm{p}=0.03)$.

\section{Comparison between nSOREMP Positive and Negative Group Based on the Type of Narcolepsy}

Based on the type of narcolepsy and the presence of nSOREMP, subjects were further categorized into four groups (Table 2). The prevalence of nSOREMP in T1N subjects was significantly higher than that in T2N subjects ( $54.17 \%$ vs. $18.31 \%)$. There was no significant difference in demographic data (age, BMI, or sex). HLA DQB1*06:02 positivity was significantly different in both $\mathrm{T} 1 \mathrm{~N}$ and $\mathrm{T} 2 \mathrm{~N}$ groups $(\mathrm{p}=0.04, \mathrm{p}=0.03)$. In T2N, ESS of the nSOREMP positive group was significantly higer than that of the nSOREMP negative group $(15.50 \pm 4.42$ vs. $12.63 \pm 4.09$, $\mathrm{p}$ $<0.05)$. Except for ESS in T2N, there were no significant differences in daytime sleepiness parameters, including ESS and the number of naps.

In both T1N and T2N, the nSOREMP positive group showed significantly shorter MSL in MSLT (both $\mathrm{p}<0.05$ ). MSL of the nSOREMP positive group was $1.54 \pm 1.12 \mathrm{~min}$ in $\mathrm{T} 1 \mathrm{~N}$ and 1.90 \pm 1.27 in $\mathrm{T} 2 \mathrm{~N}$, while that of the nSOREMP negative group was 
Table 2. Demographic, clinical, and laboratorial findings of narcolepsy patients based on the type of narcolepsy and presence of nSOREMP

\begin{tabular}{|c|c|c|c|c|c|c|}
\hline \multirow[b]{2}{*}{ Presence of nSOREMPs } & \multicolumn{3}{|c|}{ Type 1 narcolepsy $(\mathrm{n}=96)$} & \multicolumn{3}{|c|}{ Type 2 narcolepsy $(\mathrm{n}=71)$} \\
\hline & $\begin{array}{c}\text { Present } \\
(\mathrm{n}=52,54.17 \%)\end{array}$ & $\begin{array}{c}\text { Absent } \\
(\mathrm{n}=44,45.83 \%)\end{array}$ & $\begin{array}{c}\mathrm{p}^{-} \\
\text {value }\end{array}$ & $\begin{array}{c}\text { Present } \\
(\mathrm{n}=13,18.31 \%)\end{array}$ & $\begin{array}{c}\text { Absent } \\
(\mathrm{n}=58,81.69 \%)\end{array}$ & $\begin{array}{c}\mathrm{p}- \\
\text { value }\end{array}$ \\
\hline \multicolumn{7}{|l|}{ Demographic data } \\
\hline Age, mean \pm SD (years) & $31.54 \pm 13.58$ & $28.22 \pm 13.71$ & 0.15 & $22.46 \pm 7.11$ & $27.37 \pm 13.03$ & 0.36 \\
\hline BMI, mean $\pm \mathrm{SD}\left(\mathrm{kg} / \mathrm{m}^{2}\right)$ & $24.23 \pm 3.28$ & $24.18 \pm 3.80$ & 0.72 & $24.91 \pm 3.83$ & $24.28 \pm 4.44$ & 0.52 \\
\hline Sex (male, \%) & 53.84 & 53.33 & 0.96 & 76.92 & 74.58 & 0.86 \\
\hline HLA-DQB1*06:02 (+, \%) & $79.0(\mathrm{n}=43)$ & $52.94(\mathrm{n}=34)$ & $0.04^{* *}$ & $70.00(\mathrm{n}=10)$ & $32.56(n=43)$ & $0.03^{* *}$ \\
\hline \multicolumn{7}{|l|}{ Daytime sleepiness } \\
\hline ESS & $14.72 \pm 3.68(\mathrm{n}=40)$ & $15.57 \pm 4.66(\mathrm{n}=34)$ & 0.37 & $15.50 \pm 4.42(\mathrm{n}=10)$ & $12.63 \pm 4.09(\mathrm{n}=44)$ & $0.05^{* *}$ \\
\hline Number of naps & $6.31 \pm 3.42(\mathrm{n}=32)$ & $6.28 \pm 3.04(\mathrm{n}=22)$ & 0.16 & $4.21 \pm 1.62(\mathrm{n}=7)$ & $4.40 \pm 2.28(\mathrm{n}=31)$ & 0.32 \\
\hline \multicolumn{7}{|l|}{ MSLT } \\
\hline Mean sleep latency (min) & $1.54 \pm 1.12$ & $4.05 \pm 2.93$ & $<0.05$ & $1.90 \pm 1.27$ & $4.49 \pm 2.55$ & $<0.05$ \\
\hline $\begin{array}{l}\text { SOREMPs in MSLT, } \\
\text { mean } \pm \text { SD }\end{array}$ & $3.55 \pm 0.70$ & $2.47 \pm 1.10$ & $<0.05$ & $3.46 \pm 0.66$ & $2.53 \pm 0.88$ & $<0.05$ \\
\hline \multicolumn{7}{|l|}{ Nocturnal PSG } \\
\hline $\mathrm{TIB}$, mean $\pm \mathrm{SD}(\min )$ & $458.41 \pm 35.11$ & $457.75 \pm 28.77$ & 0.99 & $464.08 \pm 19.93$ & $463.01 \pm 27.89$ & 0.90 \\
\hline $\mathrm{TST}$, mean $\pm \mathrm{SD}(\min )$ & $423.08 \pm 53.23$ & $423.31 \pm 46.06$ & 0.86 & $444.50 \pm 33.50$ & $448.37 \pm 32.22$ & 0.67 \\
\hline $\mathrm{SE}$, mean $\pm \mathrm{SD}(\%)$ & $91.91 \pm 8.90$ & $91.89 \pm 8.72$ & 0.71 & $95.13 \pm 4.59$ & $95.68 \pm 5.50$ & 0.43 \\
\hline $\mathrm{N} 1$, mean $\pm \mathrm{SD}(\%)$ & $10.97 \pm 5.99$ & $9.71 \pm 5.80$ & 0.23 & $8.76 \pm 5.35$ & $6.07 \pm 5.02$ & $0.05^{* *}$ \\
\hline $\mathrm{N} 2$, mean $\pm \mathrm{SD}(\%)$ & $50.21 \pm 10.64$ & $52.46 \pm 8.35$ & 0.31 & $52.31 \pm 7.48$ & $56.98 \pm 9.08$ & $<0.05$ \\
\hline SWS, mean \pm SD (\%) & $7.69 \pm 9.16$ & $7.24 \pm 8.46$ & 0.80 & $4.25 \pm 4.80$ & $3.13 \pm 4.21$ & 0.50 \\
\hline $\mathrm{REM}$, mean $\pm \mathrm{SD}(\%)$ & $21.46 \pm 7.70$ & $19.23 \pm 5.75$ & 0.21 & $22.10 \pm 5.25$ & $21.38 \pm 5.24$ & 0.52 \\
\hline $\mathrm{REML}$, mean $\pm \mathrm{SD}(\min )$ & $3.19 \pm 3.65$ & $92.13 \pm 47.69$ & $<0.05$ & $4.15 \pm 3.16$ & $91.59 \pm 39.33$ & $<0.05$ \\
\hline $\mathrm{SL}$, mean $\pm \mathrm{SD}(\min )$ & $2.99 \pm 3.11$ & $7.92 \pm 7.94$ & $<0.05$ & $3.95 \pm 3.29$ & $6.80 \pm 11.18$ & 0.27 \\
\hline AHI, mean \pm SD $(/ \mathrm{h})$ & $4.36 \pm 9.35$ & $5.10 \pm 10.81$ & 0.70 & $6.15 \pm 16.06$ & $4.01 \pm 7.84$ & 0.60 \\
\hline $\mathrm{PLMI}$, mean $\pm \mathrm{SD}(/ \mathrm{h})$ & $6.80 \pm 15.36$ & $3.79 \pm 9.55$ & 0.31 & $5.75 \pm 14.20$ & $2.80 \pm 9.37$ & 0.62 \\
\hline Number of awakenings & $9.47 \pm 9.51(\mathrm{n}=51)$ & $7.72 \pm 6.89(\mathrm{n}=43)$ & 0.70 & $3.85 \pm 5.03(n=13)$ & $4.70 \pm 5.48(n=53)$ & 0.60 \\
\hline TAI & $13.81 \pm 8.81(\mathrm{n}=51)$ & $12.41 \pm 10.1(\mathrm{n}=43)$ & 0.35 & $13.04 \pm 14.92(\mathrm{n}=13)$ & $9.79 \pm 7.09(\mathrm{n}=53)$ & 0.48 \\
\hline
\end{tabular}

${ }^{* *} \mathrm{p}<0.05$.

BMI: body mass index, ESS: epworth sleepiness scale, MSLT: multiple sleep latency test, nSOREMPS: nocturnal sleep-onset rapid eye movement periods, PSG: polysomnography, TIB: time in bed, TST: total sleep time, SE: sleep efficiency, N1: stage 1 sleep, N2: stage 2 sleep, SWS: slow wave sleep, REM: rapid eye movement, REML: rapid eye movement latency, SL: sleep latency, AHI: apnea hypopnea index, PLMI: periodic limb movement index, TAI: total arousal index, SD: standard deviation, HLA: human leukocyte antigen.

$4.05 \pm 2.93 \mathrm{~min}$ in $\mathrm{T} 1 \mathrm{~N}$ and $4.49 \pm 2.55 \mathrm{~min}$ in T2N. Furthermore, both $\mathrm{T} 1 \mathrm{~N}$ and $\mathrm{T} 2 \mathrm{~N}$ showed statistically higher numbers of SOREMPs in the nSOREMP positive group $(\mathrm{p}<0.05, \mathrm{p}=$ 0.001). The number of SOREMPs in MSLT within the nSOREMP positive group was $3.55 \pm 0.70$ in $\mathrm{T} 1 \mathrm{~N}$ and $3.46 \pm 0.66$ in $\mathrm{T} 2 \mathrm{~N}$, while that within the nSOREMP negative group was $2.47 \pm 1.10$ in $\mathrm{T} 1 \mathrm{~N}$ and $2.53 \pm 0.88$ in $\mathrm{T} 2 \mathrm{~N}$.

Among sleep parameters measured by PSG, both T1N and T2N failed to show significant difference in TIB, TST, or SE (all $\mathrm{p}>0.05$ ). However, in $\mathrm{T} 2 \mathrm{~N}$ subjects, the percentage of $\mathrm{N} 1$ was significantly higher in the nSOREMP positive group $(\mathrm{p}=0.05)$, while the percentage of N2 was significantly lower $(\mathrm{p}<0.05)$. Between nSOREMP positive and negative groups, differences in the percentage of $\mathrm{N} 1$ and $\mathrm{N} 2$ were not significant either in $\mathrm{T} 1 \mathrm{~N}(\mathrm{p}=0.23$ and $\mathrm{p}=0.31$, respectively). The percentage of $\mathrm{N} 1$ in the nSOREMP positive group was $10.97 \pm 5.99 \%$ in $\mathrm{T} 1 \mathrm{~N}$ and $8.76 \pm 5.35 \%$ in $\mathrm{T} 2 \mathrm{~N}$, while that in the nSOREMP negative group was $9.71 \pm 5.80 \%$ in $\mathrm{T} 1 \mathrm{~N}$ and $6.07 \pm 5.02 \%$ in $\mathrm{T} 2 \mathrm{~N}$.

Moreover, the percentage of $\mathrm{N} 2$ in the nSOREMP positive group was $50.21 \pm 10.64 \%$ in $\mathrm{T} 1 \mathrm{~N}$ and $52.31 \pm 7.48 \%$ in $\mathrm{T} 2 \mathrm{~N}$, while that in the nSOREMP negative group was $52.46 \pm 8.35 \%$ in $\mathrm{T} 1 \mathrm{~N}$ and $56.98 \pm 9.08 \%$ in T2N. However, there was no statistical difference in the percentage of REM or slow wave sleep between nSOREMP positive and negative groups (all p > 0.05). Along with MSLT data, REM latency was significantly shorter in the nSOREMP positive group than that in the in the nSOREMP 
negative group in both $\mathrm{T} 1 \mathrm{~N}$ subjects $(3.19 \pm 3.65 \mathrm{~min}$ vs. 92.13 $\pm 47.69 \mathrm{~min}, \mathrm{p}<0.05)$ and $\mathrm{T} 2 \mathrm{~N}$ subjects $(4.15 \pm 3.16 \mathrm{~min}$ vs. $91.59 \pm 39.33 \mathrm{~min}, \mathrm{p}<0.05)$. In T1N, SL of the nSOREMP positive group $(2.99 \pm 3.11 \mathrm{~min})$ was significantly shorter than that of the nSOREMP negative group (7.92 $\pm 7.94 \mathrm{~min})$. However, the difference in SL was not statistically significant in T2N subjects $(p=0.27)$. Additionally, there was no statistical difference in AHI, PLMI, number of awakenings, or TAI between nSOREMP positive and negative groups (all $\mathrm{p}>0.05$ ).

\section{DISCUSSION}

This study is one of the few studies that have categorized narcolepsy based on the presence of nSOREMP in order to investigate the correlation between nSOREMP and symptom severity. In accordance with an earlier study [8], we defined symptom severity as the presence of cataplexy, higher ESS, shorter mean SL, and higher number of SOREMPs in MSLT. As the nSOREMP positive group was highly associated with such characteristics, the presence of nSOREMP might denote a novel predictor of the severity of narcolepsy.

Subjects with nSOREMP tended to present more severe symptoms of narcolepsy. They reported shorter mean SL and higher number of SOREMPs in MSLT. Moreover, they demonstrated higher percentage of N1 and shorter SL in PSG. With their higher prevalence of cataplexy and TAI, they are more likely to show similar diagnostic features with T1N [9]. Our results were concordant with previous studies revealing that subjects with $\mathrm{T} 1 \mathrm{~N}$ were more likely to show higher percentage of N1 and nocturnal sleep disturbance compared to subjects with T2N [10,11]. This implies that the quality of life and sleep of the nSOREMP positive group might be worse than those of the nSOREMP negative group because health-related quality of life and daytime sleepiness of patients with T1N have been found to be lower than those of patients with T2N [12-14].

Another interesting finding was that the difference between nSOREMP positive and negative groups was more obvious in T2N. Subjects with nSOREMP presented significantly higher percentage of $\mathrm{N} 1$ and lower percentage of $\mathrm{N} 2$. Since $\mathrm{N} 1$ is a more alert state than N2, we considered that subjects with nSOREMP might be experiencing more unstable sleep than subjects without nSOREMP. In fact, the nSOREMP positive group also demonstrated significantly lower ESS than the nSOREMP negative group. Showing lower quality of sleep and higher daytime sleepiness, T2N subjects were more notably affected by the presence of nSOREMP. Thus, we considered nSOREMP as a potential marker of the severity of narcolepsy, especially in T2N. This may help us diagnose $\mathrm{T} 2 \mathrm{~N}$ whose diagnosis has been challenging even with MSLT and HLA typing [5,15].

Lastly, our study revealed a high correlation between nSOREMP and HLA DQB1*06:02 positivity. Subjects with nSOREMP showed significantly higher prevalence of HLA positivity. Since earlier studies have also suggested that HLA positivity is highly correlated with cataplexy $[16,17]$, the nSOREMP positive group would be more likely to have cataplexy. Indeed, the nSOREMP positive group disclosed significantly higher prevalence of cataplexy compared to the nSOREMP negative group. Our findings therefore support that nSOREMP is a possible mediating factor between genetic marker of narcolepsy and prevalence of cataplexy.

Our study has several limitations. First, our results might have been impacted by site selection bias because all sleep data were collected and analyzed in one sleep clinic. Also, all diagnostic tests were performed once. Thus, there might be a possibility of parameter changes. Despite these aforementioned limitations, the presence of nSOREMP potentially indicates the severity of narcolepsy.

\section{Conflicts of Interest}

The authors have no financial conflicts of interest.

\section{Authors' Contribution}

Conceptualization: Hong SC, Kim TW, Song J. Data curation: Kim TW, Kim SM, Um YH, Song J. Formal analysis: Kim TW. Investigation: Kim TW, Song J. Methodology: Kim TW, Song J. Project administration: Hong SC, Jeong JH. Resources: Kim TW, Kim SM, Um YH, Jeong JH, Seo HJ, Oh JH, Hong SC. Software: Oh JH. Supervision: Hong SC. Validation: Seo HJ. Writing_original draft: Kim TW, Song J. Writing-review \& editing: Um YH, Song J.

\section{REFERENCES}

1. Scheer D, Schwartz SW, Parr M, Zgibor J, Sanchez-Anguiano A, Rajaram L. Prevalence and incidence of narcolepsy in a US health care claims database, 2008-2010. Sleep 2019;42. pii: zsz091.

2. Reiter J, Katz E, Scammell TE, Maski K. Usefulness of a nocturnal SOREMP for diagnosing narcolepsy with cataplexy in a pediatric population. Sleep 2015;38:859-65

3. Andlauer O, Moore H, Jouhier L, Drake C, Peppard PE, Han F, et al. Nocturnal rapid eye movement sleep latency for identifying patients with narcolepsy/hypocretin deficiency. JAMA Neurol 2013;70:891-902.

4. Pizza F, Vandi S, Iloti M, Franceschini C, Liguori R, Mignot E, et al. Nocturnal sleep dynamics identify narcolepsy type 1. Sleep 2015;38:127784.

5. Baumann CR, Mignot E, Lammers GJ, Overeem S, Arnulf I, Rye D, et al. Challenges in diagnosing narcolepsy without cataplexy: a consensus statement. Sleep 2014;37:1035-42.

6. American Academy of Sleep Medicine. International classification of sleep disorders-third edition (ICSD-3). Darien, IL: American Academy of Sleep Medicine;2014.

7. Hallmayer J, Faraco J, Lin L, Hesselson S, Winkelmann J, Kawashima M, et al. Narcolepsy is strongly associated with the T-cell receptor alpha locus. Nat Genet 2009;41:708-11.

8. Watson NF, Ton TG, Koepsell TD, Gersuk VH, Longstreth WT Jr. Does narcolepsy symptom severity vary according to HLA-DQB1*0602 allele status? Sleep 2010;33:29-35.

9. Dauvilliers Y, Arnulf I, Mignot E. Narcolepsy with cataplexy. Lancet 2007; 369:499-511.

10. Andlauer O. Optimising the diagnosis of narcolepsy: looking deeper into sleep studies. Sleep Med 2015;16:1556-7.

11. Roth T, Dauvilliers Y, Mignot E, Montplaisir J, Paul J, Swick T, et al. Disrupted nighttime sleep in narcolepsy. J Clin Sleep Med 2013;9:955-65. 
12. Dodel R, Peter H, Spottke A, Noelker C, Althaus A, Siebert U, et al. Health-related quality of life in patients with narcolepsy. Sleep Med 2007; 8:733-41.

13. Cho J, Kim D, Noh K, Chae S. 0678 Comparison of health related quality of life between type I and type II narocolepsy patients. Sleep 2017;40(Suppl_1):A251.

14. Baumann CR, Khatami R, Werth E, Bassetti CL. Hypocretin (orexin) deficiency predicts severe objective excessive daytime sleepiness in narcolepsy with cataplexy. J Neurol Neurosurg Psychiatry 2006;77:402-4.
15. Andlauer O, Moore H 4th, Hong SC, Dauvilliers Y, Kanbayashi T, Nishino $\mathrm{S}$, et al. Predictors of hypocretin (orexin) deficiency in narcolepsy without cataplexy. Sleep 2012;35:1247-55.

16. Krahn LE, Pankratz VS, Oliver L, Boeve BF, Silber MH. Hypocretin (orexin) levels in cerebrospinal fluid of patients with narcolepsy: relationship to cataplexy and HLA DQB1*0602 status. Sleep 2002;25:733-6.

17. Han F, Lin L, Schormair B, Pizza F, Plazzi G, Ollila HM, et al. HLA DQB1*06:02 negative narcolepsy with hypocretin/orexin deficiency. Sleep 2014;37:1601-8. 